\title{
Do epinephrine auto-injectors have an unsuitable needle length for young children?
}

\author{
Laura Kim ${ }^{1 *}$, Immaculate FP Nevis ${ }^{2}$, Gina Tsai ${ }^{3}$, Arunmozhi Dominic ${ }^{3}$, Ryan Potts ${ }^{4}$, Jack Chiu ${ }^{3}$, Harold Kim²,3 \\ From Canadian Society of Allergy and Clinical Immunology Annual Scientific Meeting 2013 \\ Toronto, Canada. 3-6 October 2013
}

\section{Background}

Epinephrine delivered by an auto-injector to the anterolateral aspect of the thigh is the standard of care for the emergency treatment of anaphylaxis. For most pediatric patients in Canada, the EpipenJr ${ }^{\mathbb{B}}$ is prescribed, which has a needle length of $12.7 \mathrm{~mm}$. The route of epinephrine administration affects its onset of action, and intramuscular delivery is recommended for rapid absorption. If epinephrine is injected subcutaneously, the absorption will be slower. Conversely, if it is injected into the bone, the absorption will be unpredictable. There are no published clinical studies assessing whether the needle length of the Epipen $\mathrm{r}^{\circledR}$ is adequate to deliver epinephrine intramuscularly in pediatric patients at risk of anaphylaxis.

\section{Methods}

Consecutive pediatric patients under $15 \mathrm{~kg}$ with confirmed food allergy who required prescriptions or refills of EpipenJr ${ }^{\circledR}$ at an allergist's office were included in this study. An ultrasound of the anterolateral aspect of the mid thigh was performed under minimal $(\min )$ and maximal $(\max )$ pressure. Measurements of skin-to-muscle depth (STMD) and skin-to-bone depth (STBD) were completed. Baseline characteristics between two patient groups were compared: patients with $\mathrm{STBD}_{\max }$ less than $12.7 \mathrm{~mm}$ and patients with $\mathrm{STBD}_{\max }$ greater than or equal to $12.7 \mathrm{~mm}$. Multivariable linear regression was performed including variables such as age, sex, BMI and race. The likelihood of the $\mathrm{STBD}_{\max }$ of less than $12.7 \mathrm{~mm}$ was calculated for the weight groupings of $<9 \mathrm{~kg},<11 \mathrm{~kg}$ and $<15 \mathrm{~kg}$.

\section{Results}

A total of 75 participants were included in this study. There were 21 patients $(28 \%)$ that had $\mathrm{STBD}_{\max }$ less than $12.7 \mathrm{~mm}$. Baseline characteristics differed significantly for height and weight of the participants between the two groups $(\mathrm{p}<0.05)$. Multivariable linear regression showed that age $(\mathrm{p}=0.0002)$ and BMI $(\mathrm{p}=0.00008)$ were significantly associated with $\mathrm{STBD}_{\max }$, following adjustment for sex and race. For patients under $9 \mathrm{~kg}, 90 \%$ had $\mathrm{STBD}_{\max }$ less than $12.7 \mathrm{~mm}$. For patients under $11 \mathrm{~kg}$, $53 \%$ had $\mathrm{STBD}_{\max }$ less than $12.7 \mathrm{~mm}$.

\section{Conclusions}

Based on this study, there are a significant number of children under $15 \mathrm{~kg}$ at risk of receiving an epinephrine autoinjector into the bone. Because of this risk, epinephrine auto-injectors should be prescribed with caution in this population.

\section{Authors' details}

${ }^{1}$ Department of Anatomy and Cell Biology, McGill University, Montreal, Quebec, Canada, H3A 0G4. ${ }^{2}$ Michael DeGroote School of Medicine, McMaster University, Hamilton, Ontario, Canada, L8S 4L8. ${ }^{3}$ Schulich School of Dentistry and Medicine, Western University, London, Ontario, Canada, N6A 3K7. ${ }^{4}$ Department of Biology, University of Waterloo, Waterloo, Ontario, Canada, N2L $3 G 1$.

Published: 3 March 2014

doi:10.1186/1710-1492-10-S1-A19

Cite this article as: Kim et al:: Do epinephrine auto-injectors have an unsuitable needle length for young children? Allergy, Asthma \& Clinical Immunology 2014 10(Suppl 1):A19.

\footnotetext{
* Correspondence: laurakimkw@gmail.com

'Department of Anatomy and Cell Biology, McGill University, Montreal,

Quebec, Canada, H3A 0G4

Full list of author information is available at the end of the article
} 